\title{
GLIMPSE STUDY: IMPACT OF TRIPLE THERAPY ON LUNG FUNCTION, HEALTH STATUS, AND MORTALITY RISK IN PATIENTS WITH ADVANCED CHRONIC OBSTRUCTIVE PULMONARY DISEASE
}

\author{
SALVA FATIMA HEBA ${ }^{1 *}$, SYED AAMIR ALI' ${ }^{1}$, MOHAMMED ALEEMUDDIN NAVEED ${ }^{2}$, SALWA MEHRIN ${ }^{1}$, \\ MAARIA GULNAAZ ${ }^{1}$, NAUSHEEN FATIMA
}

${ }^{1}$ Department of Pharmacy Practice, Deccan School of Pharmacy, Darussalam, Aghapura, Hyderabad, Telangana, India. ${ }^{2}$ Department of Respiratory Medicine, Deccan College of Medical Sciences, DMRL "X" Road, Kanchanbagh, Hyderabad, Telangana, India

Email: heba33fatima@gmail.com

Received: 22 August 2020, Revised and Accepted: 04 December 2020

ABSTRACT

Objectives: The objectives of the study were to estimate the relative impact of triple therapy on lung function, health status, and mortality risk compared with combination inhaled corticosteroid (ICS)/long-acting $\beta$-agonist (LABA) therapy in symptomatic chronic obstructive pulmonary disease (COPD) patients with frequent exacerbations in an Indian clinical population.

Methods: The GLIMPSE (Lung Function, Health Status, and Mortality Risk Assessment in COPD using Triple Therapy) was as a prospective, parallel design, single-center observational study comparing 24 weeks of triple therapy (twice-daily combination of budesonide [BUD]-formoterol [FOR] [100/6 $\mu \mathrm{g}$ ] and once-daily tiotropium [TIO] [9 $\mu \mathrm{g}]$ ) with ICS/LABA (twice daily BUD-FOR [100/6 $\mu \mathrm{g}]$ ). The primary outcome was the mean change in forced expiratory volume in the $1^{\text {st }} \mathrm{s}$ (FEV1\%) predicted and COPD assessment test total score from baseline at week 24. Secondary outcomes were variation in dyspnea grade and BODE total score from baseline.

Results: At week 24 in triple therapy $(\mathrm{n}=70)$ and ICS/LABA therapy (n=70), mean difference from baseline in FEV1\% predicted were 5.40 (95\% confidence interval [CI]: 1.29-9.50) and 1.90 (95\% CI: -1.87-5.68) respectively, and mean difference in CAT total score from baseline was -5.10 units (95\% CI: -3.49--6.71) and -1.80 units (95\% CI: -0.052--3.548), respectively. In addition, there was a statistically significant reduction in dyspnea grading and BODE score with comparable adverse events in both groups.

Conclusion: Overall, the results favored triple therapy over dual therapy in advanced symptomatic COPD patients.

Keywords: Chronic obstructive pulmonary disease, Triple therapy, Lung function, Health status, Mortality risk.

(C) 2021 The Authors. Published by Innovare Academic Sciences Pvt Ltd. This is an open access article under the CC BY license (http://creativecommons.org/ licenses/by/4.0/) DOI: http://dx.doi.org/10.22159/ajpcr.2021v14i1.39505. Journal homepage: https://innovareacademics.in/journals/index.php/ajpcr

\section{INTRODUCTION}

The global initiative for chronic obstructive lung disease (GOLD) management approach at present suggests the use of triple therapy (combination inhaled corticosteroid [ICS]+long-acting $\beta$-agonist [LABA]+long-acting muscarinic antagonist [LAMA]) in advanced chronic obstructive pulmonary disease (COPD) patients with chronic symptoms and at increased possibility of exacerbation despite maximal dual bronchodilation or glucocorticoid-LABA. Triple therapy may provide a greater enhancement in lung function and health status compared with ICS/LABA dual therapy [1-4]. So far, trials that studied dual therapy and triple therapy directly are minimal, both in quantity and extent and only a couple of randomized controlled trials showed prolonged improvement in lung function and health status compared with ICS/LABA alone [5].

The lung function, health status, and mortality risk assessment in COPD using triple therapy (GLIMPSE) study is the first study in an Indian clinical setting to specifically compare multiple inhaler triple therapy (ICS/LAMA/LABA) with dual therapy (ICS/LABA) in advanced, symptomatic COPD patients at a higher risk of exacerbations. GLIMPSE was particularly aimed to have direct similarity to the real-life medical practice. We recruited patients who had forced expiratory volume in the $1^{\text {st }} \mathrm{s}$ (FEV1\%) $<50 \%$ and $50-80 \%$, COPD assessment test (CAT) score of more than or equal to 10 , and an exacerbation history in a manner that all the patients were recruited in accordance with the GOLD criteria. At present, GOLD guidelines recommend triple therapy as an option for these patients. Conversely, in clinical practice, triple therapy is not usually considered a first-line approach; rather, it is generally escalated from monotherapy or dual therapy, probably due to the lack of evidence supporting this approach. We used the same agents and same doses in dual therapy as well as triple therapy.

\section{METHODOLOGY}

\section{Trial design and oversight}

GLIMPSE was a prospective, non-interventional, open-label, parallelgroup, and comparative 24-week study in an Indian tertiary care teaching hospital. Due to the smaller sample size, the study was conducted as a pilot study. Overall, 80 patients were recruited who were receiving COPD maintenance therapy for past 3 months and were divided into two groups of 70 each. Moreover, recruitment was based on sampling convenience. Patients were assigned to receive either (1) twice daily combination of budesonide (BUD)/formoterol (FOR) $(100 \mu \mathrm{g} / 6 \mu \mathrm{g})$ and once-daily tiotropium (TIO) (9 $\mu \mathrm{g})$ in single inhaler or (2) twice daily combination of BUD/FOR $(100 \mu \mathrm{g} / 6 \mu \mathrm{g})$ in single inhaler. ICS/LABA dual-combination product of BUD/FOR was selected as a comparator as it is well known, readily available, and the most used medication by COPD patients in India. Patients took two puffs of BUD/ FOR (once in the morning and once in the evening) and one puff of TIO to reduce the influence of divergent dosing regimens.

During the 6 months study period patients, patients who remained on the study were called every 12 and 24 weeks for efficacy and safety 
assessment. Patients who discontinued the study drug and who lost to follow-up were excluded from the study. Specific measures were taken to ensure that the patients remain on the study drug until the endpoints were achieved.

The main objective was to estimate the relative impact of triple therapy (twice daily BUD/FOR plus once-daily TIO) on lung function, health status, and mortality risk compared with a dual therapy of twice-daily BUD/FOR in symptomatic COPD patients with a history of frequent exacerbation in an Indian clinical setting.

\section{Ethical approval}

The study was authorized by the ethics committee or institutional review board and was compiled in accordance with the Declaration of Helsinki and the International Conference on Harmonisation Good Clinical Practice (ICH/CPMP/135/95). Written informed consent was obtained from all the subjects before enrollment.

\section{Study endpoints}

The primary endpoints were the change in FEV1\% predicted from baseline and the change in CAT total score from baseline at the end of week 24. Analysis includes proportion of patients showing improvement in lung function of FEV1 greater than or equal to $100 \mathrm{ml}$ from baseline and decline in CAT total score of two or more units from baseline. For the secondary endpoints measuring modified British medical research council (mMRC) grade and BODE index total score, a change in mMRC grade of more than 1 unit from baseline and decline in BODE index total score of at least one unit from baseline over 24 weeks were considered. Efficacy and safety endpoints were measured at 12 and 24 weeks in both groups.

\section{Patients}

We recruited male or female patients aged 40 years and above; current smokers, ex-smokers or non-smokers; diagnosed COPD by the American Thoracic Society (ATS)/European Respiratory Society (ERS) [6]; receiving COPD maintenance treatment of either LABA/LAMA or ICS/ LABA or LABA or LAMA alone for more than 3 months before screening and either (1) post-bronchodilator (PB) FEV in $1 \mathrm{~s}<50 \%$ predicted and 1 or more moderate or severe COPD exacerbation in prior year or (2) PB-FEV1 50-80\% predicted usual and 2 or more than 2 moderate exacerbation or 1 or more severe COPD exacerbation in previous year. The primary exclusion criteria were patients currently diagnosed of asthma, pneumonia, and other disorders of the respiratory system; age below 40 years, pregnant women or planning to conceive, alpha 1 antitrypsin deficiency, ICS/LABA/LAMA contraindications, and patients receiving triple therapy before screening.

\section{Efficacy and safety assessment}

At the initial visit, patient baseline characteristics were recorded in an electronically generated case report form having patient demographics, PB-FEV1\% predicted, CAT score, mMRC dyspnea grade, exacerbation history in previous 6 months, COPD maintenance therapy, and BODE score. Eligible patients were screened, and spirometry was recorded in all patients at baseline, at week 12 and 24 using standardized equipment in accordance with the ATS/ERS criteria [6]. PB-FEV1 and FEV1/FVC ratio were recorded.

Initial symptom assessment was done using mMRC questionnaire [7] and CAT score questionnaire [8]. Variation of two or more units in 2-3 months in patients suggests a clinically significant change in health status. A 6-min walk distance measured in a $40 \mathrm{~m}$ corridor for interpretation of BODE index for assessing mortality risk using body mass index (BMI), lung obstruction (FEV1), dyspnea grade, and exercise capacity. BODE score was interpreted in terms of an estimated percentage 4 years survival. Higher score indicates a lesser chance of 4-year survival [9]. During the 24-week treatment period, the patient attended a visit at 12 and 24 weeks.

Exacerbation incidence and safety assessment such as incidence of pneumonia together with adverse events, serious adverse events, cardiovascular events, and other events were recorded throughout the study.

\section{Statistical analysis}

Statistical analysis was performed using Epi Info Software version 7.0 (CDC, Atlanta, Georgia, USA). Sample size was calculated on the basis endpoints and the number of COPD patients who visited to the hospital during the 6 months study period. Continuous variables were expressed as mean and standard deviation, whereas categorical variables were expressed as numbers and percentages. Efficacy assessment of primary endpoints as well as secondary endpoints was all expressed as mean difference and standard deviation with corresponding 95\% confidence interval (CI). A p $<0.05$ was set as statistically significant.

\section{RESULTS}

\section{Patients}

A total of 140 patients were recruited during the 24-week study period. Patients were divided into those receiving triple therapy and dual therapy, with 70 patients in each group. Patients who discontinued the study drug or lost to follow-up were not included in the sample size. Baseline characteristics were well balanced in both the groups, shown in Table 1.

\section{Primary endpoints}

A significant change in FEV1 from baseline was observed in both the groups at the end of the study period. BUD/FOR/TIO showed marked improvement in lung function from baseline over 12- and 24-week study period (Fig. 1a, and Table 2). At week 24, mean change in FEV1\% predicted from baseline was 5.40 (95\% CI: 1.29 to 9.50) in BUD/ FOR/TIO group and 1.90 (95\% CI: -1.87 to 5.68) in BUD/FOR group and the mean difference in FEV1 was statistically significant between BUD/FOR/TIO and BUD/FOR (3.50; 95\% CI: 4.17 to 2.83; $<<0.0001$ ) (Table 2). At all the time periods, differences from baseline were greater and highly significant, favoring BUD/FOR/TIO over BUD/FOR.

For CAT total score, significant differences in mean change from baseline in total CAT score were noted between BUD/FOR/TIO and BUD/FOR, with a greater reduction in total score in patients receiving BUD/FOR/TIO (Fig. 1b). The mean change from baseline CAT score was in BUD/FOR/TIO group and in BUD/FOR group. The group differences among the treatment were statistically significant in support of BUD/ FOR/TIO (Table 2).

However, over 6 months study period, initially, a modest change in FEV1 was observed in both the groups till the end of week 12, whereas greater improvement was observed at the end of week 24 and this improvement in FEV1 from week 12 to 24 was significantly higher in BUD/FOR/TIO group compared to BUD/FOR group (Fig. 2a).

Change in CAT total score over 12 and 24 weeks was consistent with a greater reduction in the total score were achieved in a greater extent with BUD/FOR/TIO compared to BUD/FOR (Fig. 2b). In the primary efficacy analysis, BUD/FOR/TIO was superior with greater improvement in FEV1 and total CAT score from baseline compared to BUD/FOR therapy.

\section{Secondary endpoints}

For mMRC grading, relevant improvement from baseline (decrease $\geq 1$ unit) observed with BUD/FOR/TIO at all visits, with significant differences between two groups at week 12 and 24 (mean group difference at week 24; 0.17 ; 95\% CI: 0.12 to 0.22 ; p<0.0001). Patients were more probable to have significant improvement in mMRC scale with BUD/FOR/TIO (mean change from baseline: -1.10; 95\% CI: -0.81$-1.39)$ than with BUD/FOR (-0.93; 95\% CI: -0.65--1.21) at week 24 (Fig. 3a and Table 2).

For a change in BODE total score, a larger number of patients showed clinical improvement from baseline with BUD/FOR/TIO. The mean change in BODE score from baseline for BUD/FOR/TIO group was 
Table 1: Baseline characteristics of the study population

\begin{tabular}{|c|c|c|c|}
\hline Characteristics & Triple therapy $(n=70)$ & Dual therapy $(n=70)$ & Total $(n=140)$ \\
\hline Age (years) (Mean \pm SD) & 57.1 $\pm 11.8,(95 \%$ CI: 53.99-60.12) & $57.04 \pm 4.1,(95 \%$ CI: 53.95-60.08) & $57.0 \pm 12.9,(95 \%$ CI: $54.94-59.13)$ \\
\hline \multicolumn{4}{|l|}{ Gender } \\
\hline Male n (\%) & $54(77 \%)$ & $57(81 \%)$ & $111(79 \%)$ \\
\hline Female n (\%) & $16(23 \%)$ & $13(19 \%)$ & $29(21 \%)$ \\
\hline Risk factor $\mathrm{n}(\%)$ & $21 / 28 / 21(30 \% / 40 \% / 30 \%)$ & $25 / 18 / 27$ (36\%/26\%/38\%) & $46 / 46 / 48(33 \% / 33 \% / 34 \%)$ \\
\hline \multicolumn{4}{|l|}{ (Current/Ex/non-smoker) } \\
\hline \multicolumn{4}{|c|}{ Time since primary diagnosis n (\%) } \\
\hline$<1$ year & $21(30)$ & $11(16)$ & $32(23)$ \\
\hline FEV1\% predicted (Mean \pm SD) & $54.5 \pm 13.1,(95 \%$ CI: 51.55-57.36) & $55.3 \pm 11.4,(95 \%$ CI: $52.36-58.17)$ & $54.9 \pm 12.3,(95 \%$ CI: $52.77-56.95)$ \\
\hline FEV1/FVC ratio (Mean \pm SD) & $52.1 \pm 13.2$, (95\% CI: 49.16-55.07) & 53.8 $\pm 11.8,(95 \%$ CI: $50.80-56.71)$ & $52.9 \pm 12.5,(95 \%$ CI: $50.86-55.01)$ \\
\hline $\begin{array}{l}\text { Total CAT score at screening } \S \\
(\text { Mean } \pm \text { SD) }\end{array}$ & $25.9 \pm 5.29,(95 \%$ CI: $24.60-27.11)$ & $27.7 \pm 5.34,(95 \%$ CI: 26.46-28.97) & 26.8 $\pm 5.38,(95 \%$ CI: $26.05-27.52)$ \\
\hline $\begin{array}{l}\text { mMRC dyspnea grade at } \\
\text { screening } \dagger(\text { Mean } \pm S D)\end{array}$ & $2.74 \pm 0.76,(95 \%$ CI: 2.56-2.92) & $3.09 \pm 0.76,(95 \%$ CI: $2.90-3.26)$ & $2.91 \pm 0.77,(95 \%$ CI: $2.66-3.16)$ \\
\hline $\begin{array}{l}\text { Total BODE index score at } \\
\text { screening } \neq(\text { Mean } \pm S D)\end{array}$ & $6.83 \pm 2.08,(95 \%$ CI: 6.43-7.23) & $6.14 \pm 1.80,(95 \%$ CI: $5.77-6.52)$ & $6.49 \pm 1.97,(95 \%$ CI: 6.24-6.73) \\
\hline \multicolumn{4}{|c|}{ Exacerbation history in 6 months before screening n (\%); } \\
\hline 0 & $9(13)$ & $11(16)$ & $20(14)$ \\
\hline$\geq 1$ & $13(19)$ & $14(20)$ & 27 (19) \\
\hline$\geq 2$ & $48(68)$ & $45(64)$ & $93(67)$ \\
\hline \multicolumn{4}{|c|}{ COPD medications before enrollment $\mathrm{n}(\%)$} \\
\hline ICS/LABA & $22(31)$ & $26(37)$ & $48(34)$ \\
\hline ICS/LAMA & $15(21)$ & $11(16)$ & $26(19)$ \\
\hline LABA/LAMA & $12(17)$ & $15(21)$ & $27(19)$ \\
\hline LAMA & $21(30)$ & $18(26)$ & $39(28)$ \\
\hline
\end{tabular}

Plus minus implies means \pm SD; triple-therapy group patients received twice daily combination of BUD $100 \mu \mathrm{g}$ and FOR $6 \mu \mathrm{g}$ and once daily tiotropium $9 \mu \mathrm{g}$ in multiple inhaler. Dual therapy group patients received twice daily combination of BUD and FOR (100 $\mu \mathrm{g}$ and $6 \mu \mathrm{g})$ in single inhaler. *The BMI as calculated by dividing weight in kilograms by the height in square meters. Ex-smokers were described as those who discontinued smoking at least 6 months before enrollment. FEV1 implies FEV in 1 second. § Scores on the COPD assessment test (CAT) range from 0 to 40, with higher scores indicating more symptoms. The minimal clinical key difference is 2 units. †Scores on mMRC scale range from 0 to 4 , higher score indicates higher severity. The minimal clinical key difference is 1 unit. $\neq$ BODE index score ranges from 0 to 10 , higher score indicates higher risk of mortality. The minimal clinical key difference is 2 units. A moderate exacerbation of chronic obstructive pulmonary disease (COPD) was defined as an episode requiring treatment with antibiotics or systemic glucocorticoids. A severe COPD exacerbation was defined as one resulting in hospitalization or death [1]. FEV1\%: Forced expiratory volume in the $1^{\text {st }} \mathrm{s}$

Table 2: Lung function, CAT score, mMRC dyspnea grade, and BODE score response

\begin{tabular}{|c|c|c|}
\hline Outcome & Triple therapy $(n=70)$ & Dual therapy $(n=70)$ \\
\hline \multicolumn{3}{|l|}{ PB-FEV1 (\% predicted) } \\
\hline Mean at baseline \pm SD $(95 \% \mathrm{CI})$ & $54.5 \pm 13.1,(95 \%$ CI: 51.55-57.36) & $55.3 \pm 11.4,(95 \%$ CI: 52.36-58.17) \\
\hline Mean at 24 weeks \pm SD $(95 \% \mathrm{CI})$ & $59.9 \pm 11.4,(95 \%$ CI: 57.13-62.76) & 57.2 $\pm 11.2,(95 \%$ CI: 54.53-59.88) \\
\hline Mean change from baseline \pm SD $(95 \% \mathrm{CI})$ & $5.40 \pm 2.07,(95 \%$ CI: $1.29-9.50)$ & $1.90 \pm 1.91,(95 \%$ CI: $-1.87-5.68)$ \\
\hline $\begin{array}{l}\text { Difference between triple therapy and dual } \\
\text { therapy group }(95 \% \mathrm{CI}) \text {; p-value }\end{array}$ & $3.50 \pm 0.34,(95 \%$ CI: 4.17-2.83); $p<0.0001$ & \\
\hline \multicolumn{3}{|l|}{ Total cat score } \\
\hline Mean at baseline \pm SD $(95 \% \mathrm{CI})$ & $25.9 \pm 5.29,(95 \%$ CI: $24.60-27.11)$ & $27.7 \pm 5.34,(95 \%$ CI: 26.46-28.97) \\
\hline Mean at 24 weeks \pm SD $(95 \% \mathrm{CI})$ & $20.8 \pm 4,30,(95 \%$ CI: $19.75-21.90)$ & $25.9 \pm 5.12,(95 \%$ CI: $24.67-27.13)$ \\
\hline Mean change from baseline \pm SD $(95 \% \mathrm{CI}) \S$ & $-5.10 \pm 0.82,(95 \% \mathrm{CI}:-3.49--6.71)$ & $-1.80 \pm 0.88,(95 \% \mathrm{CI}:-0.052--3.54$ \\
\hline $\begin{array}{l}\text { Difference between triple therapy and dual } \\
\text { therapy group }(95 \% \mathrm{CI}) \text {; P value }\end{array}$ & $3.30 \pm 0.14,(95 \%$ CI: $3.02-3.58) ; \mathrm{p}<0.0001$ & \\
\hline \multicolumn{3}{|l|}{ Dyspnea grade } \\
\hline Mean at baseline \pm SD $(95 \% \mathrm{CI})$ & $2.74 \pm 0.76$, (95\% CI: 2.56-2.92) & $3.09 \pm 0.76$, (95\% CI: 2.90 -be 3.26$)$ \\
\hline mean at 24 weeks $\pm \mathrm{SD}(95 \% \mathrm{CI})$ & 1.64 \pm 0.95 , (95\% CI: $1.42-1.86)$ & $2.16 \pm 0.93,(95 \% \mathrm{CI}: 1.94-2.38)$ \\
\hline Mean change from baseline \pm SD $(95 \% \mathrm{CI}) \dagger$ & $-1.10 \pm 0.15$, (95\% CI: $-0.81--1.39)$ & $-0.93 \pm 0.14,(95 \%$ CI: $-0.65--1.21)$ \\
\hline $\begin{array}{l}\text { Difference between triple therapy and dual } \\
\text { therapy group }(95 \% \mathrm{CI}) \text {; p-value }\end{array}$ & $0.17 \pm 0.02$, (95\% CI: 0.12-0.22); p<0.0001 & \\
\hline \multicolumn{3}{|l|}{ Bode index } \\
\hline Mean at baseline \pm SD $(95 \% \mathrm{CI})$ & 6.83 $\pm 2.08,(95 \%$ CI: 6.43-7.23) & $6.14 \pm 1.80,(95 \%$ CI: 5.77-6.52) \\
\hline mean at 24 weeks $\pm \mathrm{SD}(95 \% \mathrm{CI})$ & $3.46 \pm 1.14,(95 \%$ CI: $3.19-3.73)$ & $3.97 \pm 1.35$, (95\% CI: 3.59-4.34) \\
\hline Mean change from baseline \pm SD $(95 \% \mathrm{CI}) \neq$ & $-3.37 \pm 0.28,(95 \% \mathrm{CI}: 2.81-3.93)$ & $-2.17 \pm 0.27,(95 \%$ CI: $1.64-2.70)$ \\
\hline $\begin{array}{l}\text { Difference between triple therapy and dual } \\
\text { therapy group ( } 95 \% \mathrm{CI}) \text {; p-value }\end{array}$ & $1.20 \pm 0.04,(95 \%$ CI: $1.11-1.29) ; \mathrm{p}<0.0001$ & \\
\hline
\end{tabular}

The means presented as means \pm SD. $p<0.001$ is considered statistically significant. $\S$ An improvement was determined as a decrease in the CAT total score of at least 2 units from the baseline value. †An improvement was determined as a decrease in the mMRC score of at least 1 unit from the baseline value. $\ddagger$ An improvement was determined as a decrease in the total BODE index score of at least 2 units from the baseline value. FEV1\%: Forced expiratory volume in the $1^{\text {st }} \mathrm{s}$, CI: Confidence interval

-3.37 (95\% CI: 2.81 to 3.93) and for BUD/FOR group was -2.17 (95\% CI: 1.64 to 2.70 ) at the end of 24 weeks (Fig. $3 \mathrm{~b}$ and Table 2). Almost all the patients had at least one-unit improvement in BODE index. Of these, $71 \%$ patients improved the BODE index by at least -2 points and $19 \%$ by -1 point. No change in BODE index was seen in $6 \%$ patients and $4 \%$ patients showed worsening of BODE index. However, a higher 


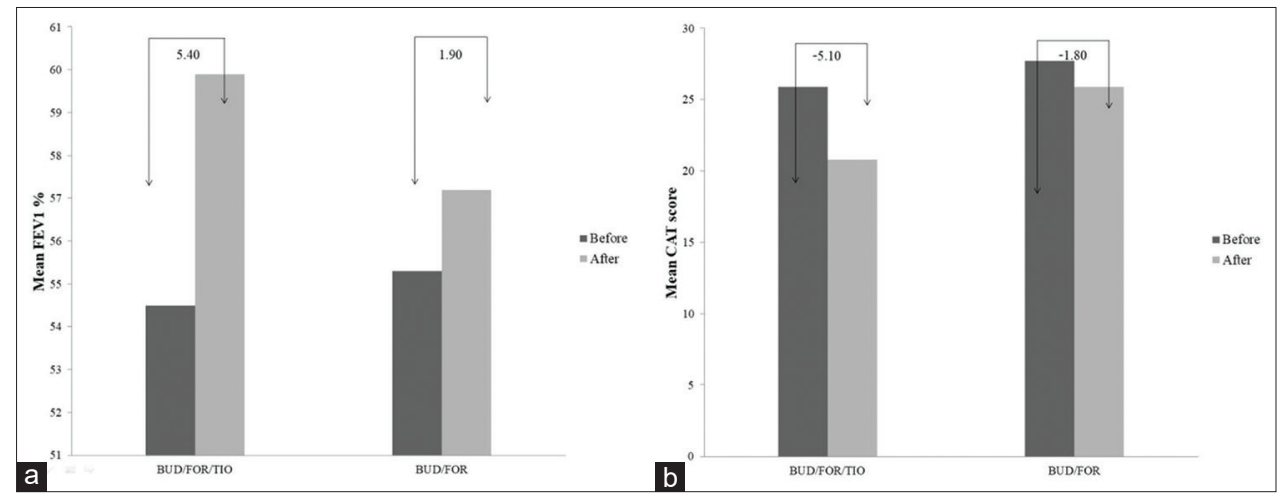

Fig. 1: Change from baseline in (a) forced expiratory volume in the $1^{\text {st }} s \%$ and (b) CAT total score over 24 weeks

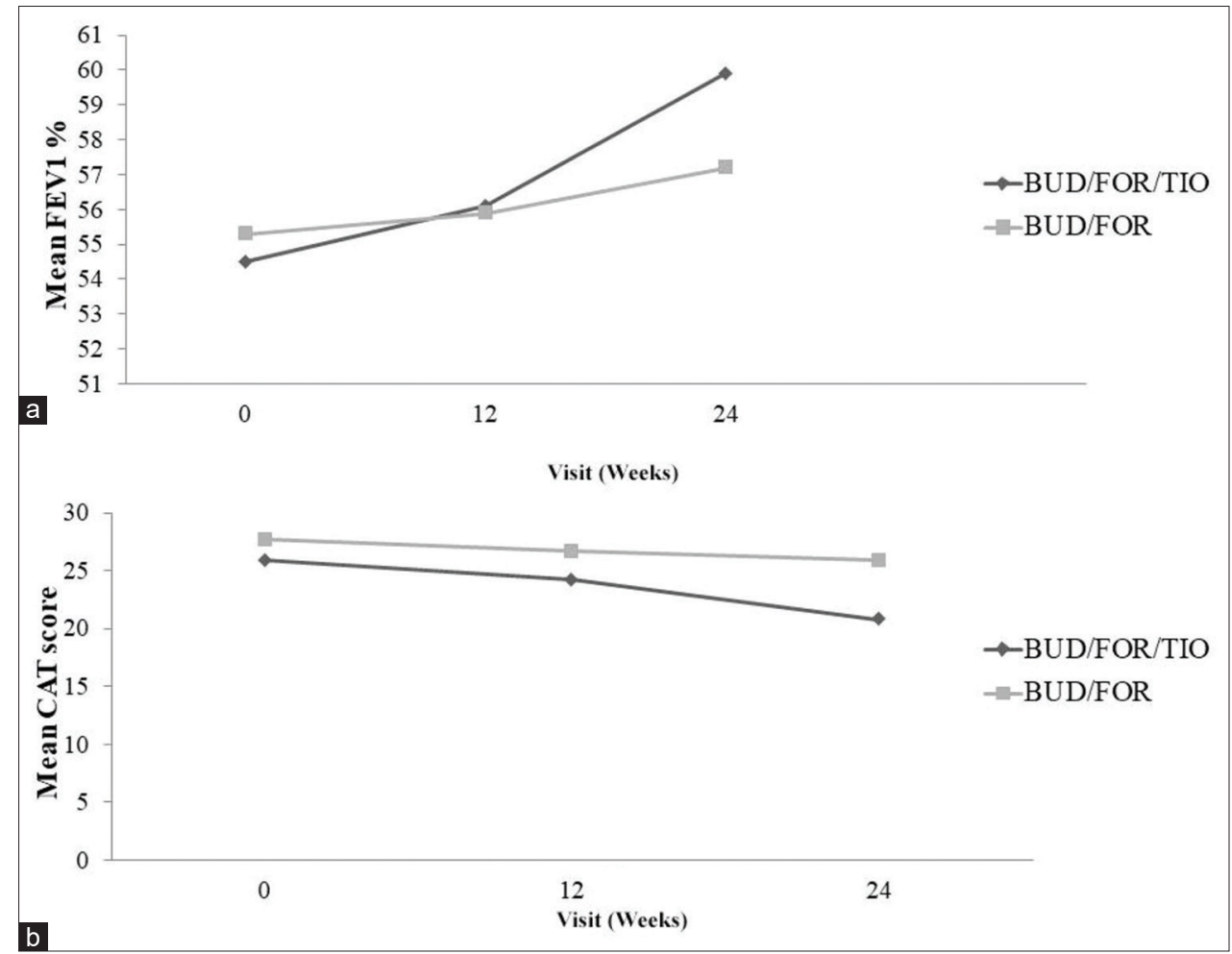

Fig. 2: Change in (a) forced expiratory volume in the $1^{\text {st }} s \%$ and (b) CAT total score over 12 and 24 weeks

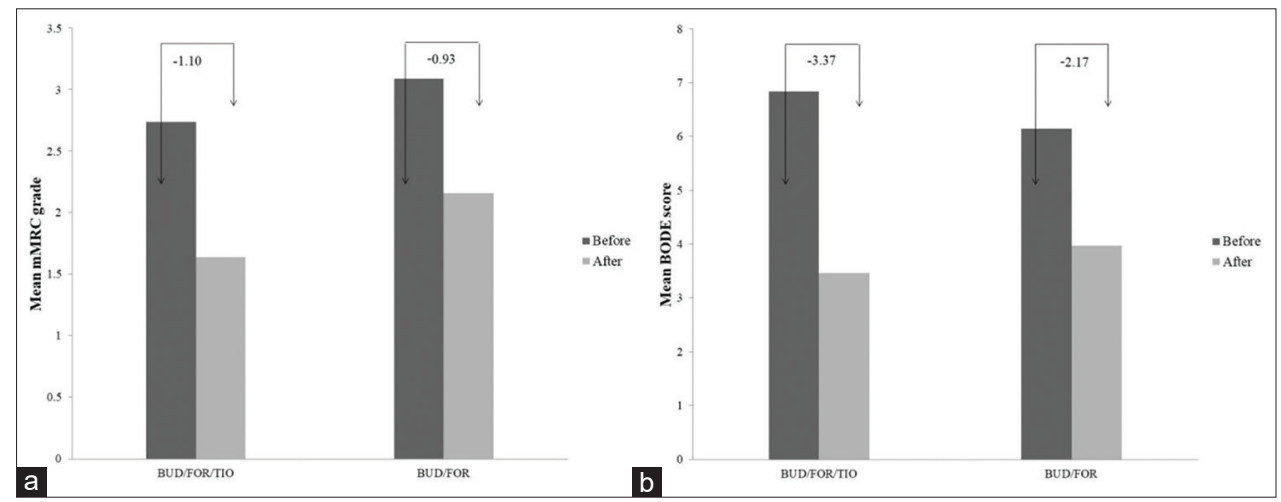

Fig. 3: Change in from baseline in (a) mMRC grade and (b) BODE total score over 24 weeks

proportion of patients in BUD/FOR/TIO group showed a greater decline in BODE index, suggesting a marked decline in risk of mortality with triple therapy compared with BUD/FOR therapy.
The number of patients experiencing moderate-to-severe and severe COPD exacerbation during the study was lower with BUD/FOR/TIO (18\%) than with BUD/FOR (25\%). Lesser number of patients was 
hospitalized in BUD/FOR/TIO ( $\mathrm{n}=12$ [17\%]) group than BUD/FOR $(\mathrm{n}=18[26 \%])$.

\section{Safety analysis}

Adverse events were comparable in both groups; most events were mild or moderate. Pneumonia was reported by $2(2.8 \%)$ patient in BUD/FOR/TIO group and 1 (1.4\%) patients in BUD/FOR group. Adverse events most commonly reported were nasopharyngitis (5\% in BUD/FOR/TIO and $8 \%$ in BUD/FOR), dry mouth (8\% in BUD/FOR/TIO and $6 \%$ in BUD/FOR), and headache $(10 \%$ in BUD/FOR/TIO and $15 \%$ in BUD/FOR) while worsening of COPD was observed in the majority of patients in BUD/FOR group (12\%) than BUD/FOR/TIO group (4\%). Likewise, cardiac events were 10\% in BUD/FOR/TIO group and 6\% in BUD/FOR group. Serious adverse events were minimal and comparable between the two groups: $8 \%$ in BUD/FOR/TIO group and 4\% in BUD/ FOR group. Serious adverse drug reaction was $1.4 \%$ in BUD/FOR/TIO group and $3 \%$ in BUD/FOR group. No deaths, no significant differences in vitals, and other variables of ECG from baseline were noted.

\section{DISCUSSION}

In particular, our results demonstrated that BUD/FOR/TIO therapy had a considerable and significant improvement in terms of lung function and health status in comparison to BUD/FOR over 24 weeks of regimen without any discrepancies in adverse events, specifically pneumonia. The improvement in health status was reflected through a substantial reduction in symptoms assessed using CAT total score and mMRC grade. At every 12- and 24-week time period, BUD/FOR/TIO expressed greater improvement in lung function and reduction in CAT total score than dual therapy of BUD/FOR. Comprehensively, analyses showed improvement in lung function with BUD/FOR/TIO resulted in clinically relevant improvement in patient symptoms and well-being in a greater proportion of patients accompanied by a decrease in the frequency of exacerbation. At the end of week 24 relevant reduction in dyspnea grade and BODE data were also observed with BUD/FOR/TIO than BUD/FOR. Chiefly, the advantages of BUD/FOR/TIO on lung function, symptom reduction, and mortality risk were persistent over 24-week study period. Likewise, the benefit of triple therapy with reference to lung function was like the results reported by previous studies with broader inclusion criteria [13,14,17-24].

Safety analysis, including the adverse events of BUD/FOR/TIO, was like the known studies of the same agents, and the results of our 24week study showed no progressive adverse effects with BUD/FOR/TIO. However, the incidence of pneumonia was high in BUD/FOR/TIO group in comparison to BUD/FOR at the end of 24 weeks. The incidence of pneumonia observed with BUD/FOR/TIO is identical with the results of distinct 24-week studies of COPD with an incident rate of up to $2 \%[11,12]$, and also in studies wherein FF/VI was administered for COPD $[13,14]$. Likewise, incidence of pneumonia was similar to one more studies of triple therapy for COPD, where $3 \%$ of patients reported with pneumonia both triple therapy and ICS/LABA therapy [15], which is less than the incidence put forward in FF/VI [16] study of 52 weeks and also with BUD/FOR [17].

However, the study was not sufficient to determine the outcome of the treatments in reducing the number and rate of exacerbation, possibly due to the smaller sample size and short duration of the study. Nonetheless, our study focused on pulmonary function and health status, there proportion of patients experiencing exacerbation during the study period was low and there exists a clear benefit favoring BUD/ FOR/TIO over BUD/FOR on both the outcomes. GLIMPSE was specifically designed to assess the potential effects of triple therapy in advanced COPD patients who experienced not less than one exacerbation history in the previous 6 months despite maximal treatment with dual therapy and those receiving COPD maintenance treatment of either LABA alone or ICS/LAMA or ICS/LABA. Patients who showed significant improvement in lung function and symptoms with the study were allowed to continue the study medication and patients who wished to use dual therapy owing to a marked improvement in lung function were allowed to have a step down in therapy after 24 weeks. The study closely reflected the real-world setting.

In this study, ICS/LABA/LAMA (BUD/FOR/TIO) was compared with ICS/LABA (BUD/FOR) in different inhalers and in different dosing regimens since no single triple inhaler was available at that time. The main objective was to estimate the relative impact of triple therapy using the most used medications by COPD patients in Indian setting. Moreover, we used the same agents and same doses of drugs in both groups. The results enumerated are straight away comparison of the agents instead of adding a LAMA to ICS/LABA.

Previously, several interventional and randomized controlled trials have previously illustrated the positive effects of triple therapy in the treatment of COPD using two separate devices or by single inhaler device. However, there is evidence in support of the step up to LAMA therapy [14,17-24] wherein three trials differentiated triple therapy with LABA/LAMA dual therapy and eleven trials differentiated triple therapy with a dual therapy of ICS-LABA. Furthermore, when compared to dual therapy, triple therapy showed significant improvement in trough FEV1 and a decline in the frequency of moderate-to-severe or severe COPD exacerbation [11]. TRILOGY and FULFIL study compared triple therapy with BUD/FOR, indicating that triple therapy had a moderate benefit in reducing exacerbation and improving health-related quality of life, although this effect declined while the study proceeded $[14,20]$. Of note, a retrospective analysis of four studies showed the benefit of Triple therapy or placebo plus ICS/LABA in improving lung function and quality of life along with the reduction in exacerbation risk over ICS/LABA therapy [18]. In like manner, similar results were obtained in other trials, TRINITY that compared single inhaler along with multiple inhaler triple therapy with LAMA monotherapy and TRIBUTE that compared triple therapy with dual therapy of LABA/LAMA $[21,22]$. However, these studies constantly demonstrated the benefits of triple therapy, mostly in-terms of exacerbation, while many also suggest an improvement regarding lung function and health status.

We admit that our study has a few limitations. We enrolled a smaller number of participants than did the other studies evaluating triple therapy and exacerbation rate was not considered as a primary outcome due to the short duration of the study. We used multiple inhalers for triple therapy due to the lack of availability of single triple inhaler during that time. Moreover, it was an observational and singlecenter study. Further extensive studies are required to be conducted on the use of triple therapy in Indian clinical setting in terms of quality of life and cost-effectiveness.

\section{CONCLUSION}

The results of the GLIMPSE study demonstrated the clinical benefits of triple therapy using BUD/FOR/TIO in comparison with BUD/FOR therapy in advanced symptomatic COPD patients who are at a higher risk of exacerbations. Triple therapy of twice-daily BUD-FOR and oncedaily TIO provides a direct option for patients with airflow limitation who experience frequent exacerbation and worsening of symptoms despite maximal treatment with dual therapy. Triple therapy may offer greater improvements in lung function and health status in conjugation with reducing the risk of mortality in advanced COPD patients.

\section{ACKNOWLEDGMENT}

We would like to thank the investigators and patients at the investigation site for their support in the conduct of this study.

\section{AUTHORS' CONTRIBUTIONS}

This work was carried out in collaboration among all authors. Author Dr. MAN was the treating physician for these COPD patients. Author SAA contributed in conceptualization, research design, data analysis and approved the final draft of manuscript. Author SFH contributed in data 
collection, data compilation, data analysis, and drafting of the paper. Author SM, MG, and NF helped in data collection and data compilation. All authors read and approved the final manuscript.

\section{CONFLICTS OF INTEREST}

All the authors declare that they have no conflicts of interest.

\section{FUNDING}

None.

\section{REFERENCES}

1. 2019 Global Strategy for Prevention, Diagnosis and Management of COPD. Available from: https://www.goldcopd.org/gold-reports.

2. American Lung Association Epidemiology and Statistics Unit. Trends in COPD. Chronic Bronchitis and Emphysema: Morbidity and Mortality; 2013. Available from: http://www.lung.org/assets/documents/research/ copd-trend-report. [Last accessed on 2016 Aug 12].

3. World Health Organization. Global Burden of Disease; 2016. Available from: http://www.who.int/topics/global_burden_of_disease. [Last accessed on 2016 Aug 12].

4. Pascoe SJ, Lipson DA, Locantore N, Barnacle H, Brealey N, Mohindra R, et al. A phase III randomised controlled trial of singledose triple therapy in COPD: The IMPACT protocol. Eur Respir J 2016;48:320-30.

5. Miller MR, Hankinson J, Brusasco V, Burgos F, Casaburi R, Coates A, et al. Standardisation of spirometry. Eur Respir J 2005;26:319-38.

6. Munari AB, Gulart AA, Dos Santos K, Venâncio RS, Karloh M, Mayer AF. Modified medical research council dyspnea scale in GOLD classification better reflects physical activities of daily living. Respir Care 2018;63:77-85.

7. MRC Dyspnoea Scale/MRC Breathlessness Scale. Available from: https://www.mrc.ukri.org/research/facilities-and-resources-forresearchers/mrc-scales/mrc-dyspnoea-scale-mrc-breathlessness-scale.

8. Cote CG, Celli BR. Pulmonary rehabilitation and the BODE index in COPD. Eur Respir J 2005;26:630-6.

9. Abd-Elaziz AA, Alwahsh RA, Abd-Elaal GA, Tameem AA. Correlation between CAT score, inflammatory markers and pulmonary function tests in patient with acute exacerbation of COPD. Egypt J Chest Dis Tuberc 2017;66:243-6.

10. Martinez FJ, Boscia J, Feldman G, Scott-Wilson C, Kilbride S, Fabbri L, et al. Fluticasone furoate/vilanterol $(100 / 25 ; 200 / 25 \mu \mathrm{g})$ improves lung function in COPD: A randomised trial. Respir Med 2013;107:550-9.

11. Kerwin EM, Scott-Wilson C, Sanford L, Rennard S, Agusti A, Barnes N, et al. A randomised trial of fluticasone furoate/vilanterol $(50 / 25 \mu \mathrm{g}$; 100/25 $\mu \mathrm{g}$ ) on lung function in COPD. Respir Med 2013;107:560-9.

12. Rennard SI, Tashkin DP, McElhattan J, Goldman M, Ramachandran S, Martin UJ, et al. Efficacy and tolerability of budesonide/formoterol in one hydrofluoroalkane pressurized metered-dose inhaler in patients with chronic obstructive pulmonary disease: Results from a 1-year randomized controlled clinical trial. Drugs 2009;69:549-65.

13. Tashkin DP, Rennard SI, Martin P, Ramachandran S, Martin UJ, Silkoff PE, et al. Efficacy and safety of budesonide and formoterol in one pressurized metered-dose inhaler in patients with moderate to very severe chronic obstructive pulmonary disease: Results of a 6-month randomized clinical trial. Drugs 2008;68:1975-2000.

14. Singh D, Papi A, Corradi M, Pavlišová I, Montagna I, Francisco C, et al. Single inhaler triple therapy versus inhaled corticosteroid plus long-acting $\beta 2$-agonist therapy for chronic obstructive pulmonary disease (TRILOGY): A double-blind, parallel group, randomised controlled trial. Lancet 2016;388:963-73.

15. Dransfield MT, Bourbeau J, Jones PW, Hanania NA, Mahler DA, Vestbo $\mathrm{J}$, et al. Once-daily inhaled fluticasone furoate and vilanterol versus vilanterol only for prevention of exacerbations of COPD: Two replicate double-blind, parallel-group, randomised controlled trials. Lancet Respir Med 2013;1:210-23.

16. Sharafkhaneh A, Southard JG, Goldman M, Uryniak T, Martin UJ. Effect of budesonide/formoterol pMDI on COPD exacerbations: A double-blind, randomized study. Respir Med 2012;106:257-68.

17. Siler TM, Kerwin E, Tombs L, Fahy WA, Naya I. Triple therapy of umeclidinium+inhaled corticosteroids/long-acting beta2 agonists for patients with COPD: Pooled results of randomized placebo-controlled trials. Pulm Ther 2016;2:43-58

18. Siler TM, Kerwin E, Sousa AR, Donald A, Ali R, Church A. Efficacy and safety of umeclidinium added to fluticasone furoate/vilanterol in chronic obstructive pulmonary disease: Results of two randomized studies. Respir Med 2015;109:1155-63.

19. Wedzicha JA, Banerji D, Chapman KR, Vestbo J, Roche N, Ayers RT, et al. Indacaterol-glycopyrronium versus salmeterol-fluticasone for COPD. N Engl J Med 2016;374:2222-34.

20. Lipson DA, Barnacle H, Birk R, Brealey N, Locantore N, Lomas DA, et al. FULFIL trial: Once-daily triple therapy for patients with chronic obstructive pulmonary disease. Am J Respir Crit Care Med 2017;196:438-46.

21. Vestbo J, Papi A, Corradi M, Blazhko V, Montagna I, Francisco C, et al. Single inhaler extrafine triple therapy versus long-acting muscarinic antagonist therapy for chronic obstructive pulmonary disease (TRINITY): A double-blind, parallel group, randomised controlled trial. Lancet 2017;389:1919-29.

22. Papi A, Vestbo J, Fabbri L, Corradi M, Prunier H, Cohuet G, et al. Extrafine inhaled triple therapy versus dual bronchodilator therapy in chronic obstructive pulmonary disease (TRIBUTE): A double-blind, parallel group, randomised controlled trial. Lancet 2018;391:1076-84.

23. Worth H, Buhl R, Criée CP, Kardos P, Mailänder C, Vogelmeier C. The 'real-life' COPD patient in Germany: The DACCORD study. Respir Med 2016;111:64-71.

24. Lipson DA, Barnhart F, Brealey N, Brooks J, Criner GJ, Day NC, et al. Once-daily single-inhaler triple versus dual therapy in patients with COPD. N Engl J Med 2018;378:1671-80. 